\title{
The Impact of ELF Concepts on Pre-service English Teachers: Instructor and Student Perspectives
}

\author{
CHIOU-LAN CHERN AND JEAN CURRAN
}

\author{
Are students and teachers in ELF courses on the same \\ wavelength?
}

\section{Introduction}

English as a lingua franca (ELF) first emerged in the academic literature at the end of the $20^{\text {th }}$ century. Since then, there has been an ever-increasing amount of research devoted to this topic. This line of research has identified new challenges that educators will likely face as their previous training and current practice might not match the changing landscape of English language use. ELF research has yielded new information related to how individuals communicate in an ELF context; therefore, most researchers have emphasized the need to fully explore the pedagogical impact of the findings from ELF research (Jenkins, 2006; Jenkins, Cogo \& Dewey, 2011; Mauranen, 2012).

Articles published on English as a lingua franca have delineated a number of characteristics of an ELF orientation towards English language learning. Those adopting an ELF perspective believe that all varieties of English are acceptable and therefore should not be evaluated against English spoken by native speakers (Jenkins, 2006; Jenkins, Cogo \& Dewey, 2011; Mauranen, 2012). Kirkpatrick (2012) has noted that the adoption of an ELF perspective in language education would encourage learners to use English successfully in multilingual contexts, and that the multilingual abilities of teachers and students would be recognized as an asset. In contrast to an English as a foreign language (EFL) model where language not conforming to native-speaker standards is perceived to be deficient or incorrect, an ELF orientation views differences from native speaker norms as part of the natural evolution in developing English language skills. Code-switching is also perceived to be a valuable skill as it enables English language learners to fill in gaps in their knowledge of English.

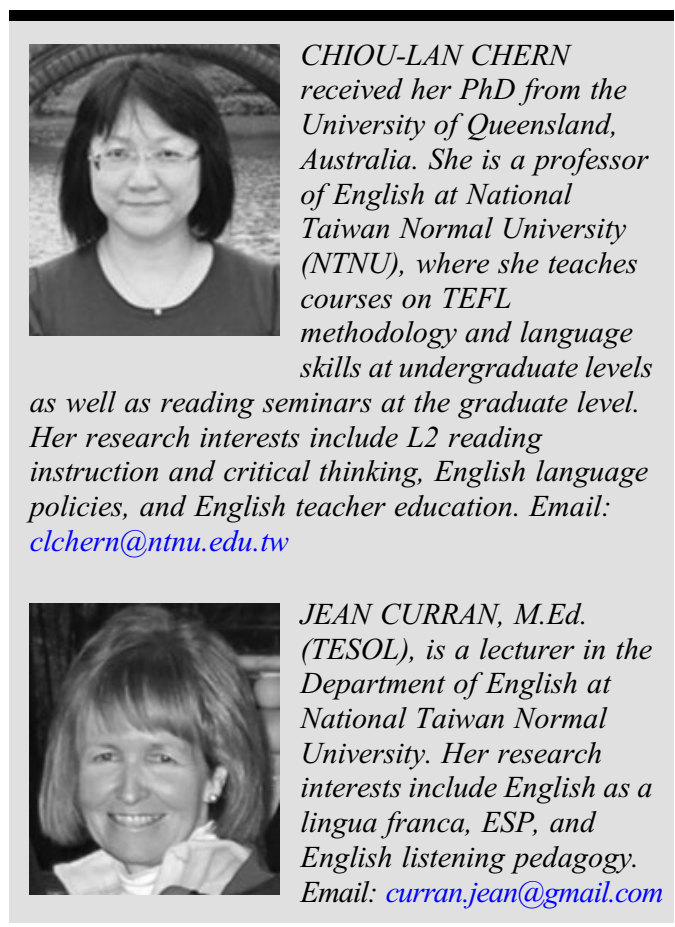


Sifakis (2007), in discussing how teachers can begin to think about incorporating an ELF perspective into their teaching practice, divided communication among non-native speakers of English into two categories: primary issues are those of linguistic and communicative concerns, including the grammar and pragmatics used among interlocutors; secondary issues are of broader scope, including the role of native speakers of English, the varieties of English, the power of English and English education policies (e.g. instructional approaches, testing, etc.). He therefore advocated a reflective and transformative approach to ELF teacher education, while cautioning that changes to long-held beliefs do not happen in short-term professional development workshops, and that this approach would therefore require participants to be involved over a long period of time.

Two recent studies (Suzuki, 2011; Dewey, 2012) investigated how individuals training to become English teachers view ELF concepts, and what the potential impact of these concepts might be on their current or future teaching practice. Dewey (2012) surveyed MA TESOL/Applied Linguistics students in United Kingdom universities to explore their knowledge of key ELF concepts. The participants came from different teaching backgrounds, and most seemed to have a sophisticated understanding and critical awareness of the issues related to English as a Global language, World Englishes, and English as a lingua franca. For example, when asked to define English as a Global Language, Dewey's participants commented on the widespread use of English in business and academic contexts and pointed out that English belongs to those who use it for communication and is not owned exclusively by native speakers. For the definition of World Englishes, they mentioned the concept of different varieties of English used in Outer Circle countries (Kachru, 1985) versus a single standard form of English. Regarding the definition of English as a lingua franca, concepts such as English used between speakers of various language backgrounds for communication, a creative simplified language to facilitate communication, and a non-codified form of English were reported. While Dewey's participants were knowledgeable about ELF theories and supported the ideas that all varieties of English should be recognized and respected, they perceived applying ELF principles to their teaching practice as very challenging. They noted that in their actual teaching situations, teachers adopted a standard form of English and educational authorities had not advocated an ELF consciousness.

Suzuki (2011) reported on the impact of a multicultural education course on the values that thirdyear Japanese undergraduates training to be English teachers held toward the concept of English for international communication. Three of the students were interviewed to gather their feedback on the lectures. For two of the students, the ideas presented in the course were quite new. The remaining student, who had been exposed to some of the ideas in another course and had had the opportunity to travel widely, credited his opportunity to travel as being highly beneficial in seeing how English is used for communication. All three students unanimously supported the principle that Japanese students need to be exposed to the idea that English is not owned by one country or culture. However, when asked how they might incorporate different varieties into the classroom when they became English teachers, the participants were more reserved. They said that because British and American English were more acceptable to Japanese, these two varieties of English should be the preferred models to adopt in class.

There has also been an increasing number of empirical studies conducted in Taiwan on the topic of English as a lingua franca (Wang \& Ho, 2013; Chien, 2014; Ke \& Cahyani, 2014; Tsou \& Chen, 2014). Most of these studies examined students' attitudes toward different varieties of English (Chien, 2014), with some focus on comparing the perceptions of ELF concepts among groups of students with varying levels of exposure to English (Wang \& Ho, 2013; Ke \& Cahyani, 2014; Tsou \& Chen, 2014). However, as little attention has been given to the effect of coursework on the development of ELF concepts, the present study, in an effort to expand upon the work already done in Taiwan, aimed to explore how an instructor's goals and expectations in a graduate course on World Englishes matched students' perceptions.

\section{Background to the study}

In spring 2012, a graduate course, Culture and English Language Teaching, was offered by a visiting professor from the United States (pseudonym, Professor Lin) with a focus on World Englishes. The themes covered included: language variation, bilingual education, linguistic diversity (World Englishes), English as a lingua franca, linguistic imperialism, English as an international language, language and identity, the role of non-native English speakers in TESOL, and language and 
race. In class, Professor Lin encouraged students to reflect critically on the relations between language, power, and social/cultural practices; she also asked them to contemplate how their perspectives on these issues would affect their roles as future teachers of English.

This one-semester course was offered once per week, three hours per session, for a total of 18 weeks. One to two weeks were spent discussing each of the aforementioned themes. The classes were conducted in a seminar format. Ten students were enrolled in the course, and were expected to present a research proposal or conduct a study that incorporated the theories and arguments discussed over the course of the semester.

In-depth interviews were conducted to tap into the participants' perceptions of ELF as a result of the course. The interviews were conducted mostly in Chinese, transcribed verbatim, and then translated into English. The questions included what the participants considered as key issues of ELF and whether they had implemented, or would implement, ELF concepts in their own teaching contexts in Taiwan. Professor Lin was also interviewed to explore her perceptions of students' reactions to the issues that were discussed in class. The interview questions asked of Professor Lin were the same as those for the participants. The following discussion will start with the instructor's point of view as she was the course designer and content provider.

\section{Voice of the Instructor}

We were first interested in the instructor's expectations for the course and of the students. Regarding course objectives, Professor Lin said:

I would like students to develop an awareness of the variety of Englishes especially in Asian regions, and also critical thinking skills, the role of Englishes, the ownership of English, and also help them to examine their own role as a future English teacher.

When asked about what she thought of students' expectations for the course, Professor Lin said:

$\ldots$ at first, they said they wanted to learn general topics about culture. Culture is such a broad topic ... But for this particular course we are going to focus on World Englishes.

The students' assumption about the content of the course was perhaps influenced by the title of the course, Culture and English Language Teaching, which had been adopted by the instructor, a visiting scholar, for administrative reasons. If the course title had specifically mentioned ELF, the students would probably have had different expectations.

When asked whether she thought students were familiar with the key concepts of ELF at the beginning of the course, Professor Lin was reserved. She said:

Some, not all of them ... some of them heard about this. Some of them probably have read articles from other courses. But my observation was ... they had very little idea about English as a lingua franca, and also World Englishes. And especially once you really talked about the ownership of English, the varieties of English, and those non-standardized language used ... Those kinds of topics were a surprise to them.

Since the course the participants took was the first ever offered in their graduate program with a focus on issues related to the current role of English in the world, the instructor's observation matched the expectations of the researchers.

When asked about students' reactions toward the idea of different varieties of English, Professor Lin said:

At first, they kind of giggled, and they thought that was very funny ... I encouraged them to use examples to talk about Chinglish or Spanglish or Singlish or different kinds of ... Thaiglish. Using the examples and talking about issues really broadened their perspectives. And then they felt there was a fine line about what was acceptable and what was not acceptable...

And they became a lot more confident and comfortable about retaining their own accent, as long as their accent did not interfere with their communication.

Professor Lin also noted that as the course progressed, the students showed more respect for other varieties of English, and that they specifically gained a new appreciation for Taiwanese English:

A key idea they took away from the course ... there are a lot of varieties (of English), and they feel empowered as a non-native speaker in this field. And Taiwanese English, there is nothing wrong with speaking Taiwanese English.

Regarding students' perceptions of the role of English in Taiwan, Professor Lin commented that students, having a shared L1, considered English as a foreign language and a school subject, rather than a language for real-life communication: 
They feel that in Taiwan ... they have not got a lot of opportunities to use English as a lingua franca (because most of the people around them speak Chinese/ Mandarin/Taiwanese). They feel more like English is a foreign language.

When English is taught as a foreign language, the focus usually falls on linguistic forms. However, when asked about the students' application of ELF ideas in classrooms in Taiwan, Professor Lin was very positive and said that her students could design teaching activities with ELF as the core concept:

... one of the projects that I asked them to do is to develop a practical lesson plan, how they would apply the World Englishes concept in the actual teaching situation, and create actual activities. Many of them did create very hands-on interactive lesson plans, and they really see that it's a way to promote world Englishes and English as a lingua franca.

Some of them are still exploring. Definitely they are moving towards that direction.

The above discussion shows that although the instructor started out with a very clear goal for the course, she became aware of students' mismatched expectations toward the topics discussed in class. In the end, she was confident that her students had started to think critically about the key concepts of ELF.

\section{Voices of the Students}

In line with Professor Lin's remarks, many students commented that the concepts associated with ELF and World Englishes were new to them when asked about their impression of the course. However, they were able to identify some key concepts of ELF, including the existence of different varieties of English rather than just the native speaker norm:

When teaching or speaking English, the goal shouldn't be native-like. We need to respect different varieties of English and different types of language used in different situations. (I-3) ${ }^{1}$

Sounding like a native speaker doesn't mean that one has good English skills, thus I don't think we should have a language education program that emphasizes sounding like a native speaker of English. (I-7)

Regarding the current practice of ELT in Taiwan, most of the participants didn't think English was considered or taught as a lingua franca in Taiwan:

If it (ELF) were being practiced, we would see different varieties of English in textbooks or being introduced by teachers. This is obviously not the case in secondary schools in Taiwan currently. (I-1)

It (ELF) hasn't been put into practice in most classrooms. If outside materials are used (Studio Classroom, Ivy League English ${ }^{2}$ ), they are based on American English, and the foreign teachers are Canadian, American, or British. This gives students fewer opportunities to be exposed to other varieties of English. (I-2)

Regarding whether the concept of ELF has influenced the way they view English, the participants exhibited some awareness of difference; some considered it important to respect all varieties of English, while others were pushed to ponder the issues addressed in the course:

Now when I watch clips on YouTube and encounter different varieties of English, I am intrigued and try to understand what the speakers are saying. (I-2)

After completing the course, I paid more attention to those who were not native speakers of English, how they pronounced words. I paid more attention to try to recognize their accents, to guess what country they came from. (I-8)

In the past when I heard some other varieties of English like Singlish, I would laugh. I now have a better understanding of how these forms of English were derived. (I-7)

These comments echoed Professor Lin's observations on students' change of perceptions and respect toward other varieties of English; when probed further regarding which parts of the concept of ELF were applicable to their own teaching contexts, the participants identified textbooks, assessments, and teaching methodologies. Many dwelled on the need to incorporate a variety of language input and multimedia resources into learning materials:

I don't want to choose a textbook that has an emphasis on American or British English - the language and culture. I'd like to see more Asian, European, or remote areas like Africa included. This would be beneficial to students' learning. (I-5)

I will teach my students that there is no standard form of English, and that we should not make fun of other forms of English considered to be non-standard ... I would try to let my students understand there are many varieties of English. I would try to expose my students to materials that introduce different varieties of English. (I-7) 
Teachers need to develop their own teaching methods. For example, teachers could play recordings introducing different varieties of English. Students need to understand and respect these different varieties. (I-1)

Nevertheless, the students felt some ambivalence about ELF. Unlike Professor Lin, who was very positive about students' endorsement of ELF concepts, the following two excerpts show that some students had doubts about the real-world applicability of the concepts learned in the course:

ELF is an important concept that should be widely taught and practiced. However, in the current exam-focused climate, what isn't included on the test is viewed as not being important. Most English teachers in Taiwan, whether consciously or unconsciously, view English as a superior language. The long-term impact is that people who can speak American or British English well are viewed with great respect. (I-2)

Most English teaching in Taiwan is focused on British or American English. Both teachers and students alike expect each other to speak English like a native speaker of English from the UK or US ... when you leave your graduate studies and return to reality ... unfortunately a certain English standard is what people use to judge each other. (I-5)

These concerns echoes Suzuki's claim that viewing American and British English as standard English 'seems to be so entrenched that it is very difficult for it to be transformed by limited instruction' (Suzuki, 2011: 152).

The above results indicate that the participants were able to grasp the essence of some ELF concepts but found it challenging to imagine how to implement them in educational settings in Taiwan. They have understood the message that there is no need to have a standard form of English and that different varieties should be respected. But they also pointed out that the overwhelming preference for and emphasis on American and British English has made it almost impossible to incorporate ELF concepts in the current English curriculum in Taiwan.

\section{Discussion and Conclusion}

Professor Lin had very clear goals for the course and was able to raise students' awareness about issues related to ELF, especially the fact that there are varieties of English and native speakers' speech should not be the norm. This seemed to be the ELF concept that struck a chord for the students. But there was also a similarity to previous studies in which the participants recognized a dilemma in considering other L2 varieties as equivalent to American or British English (Suzuki, 2011; Dewey, 2012). The participants in this study, while acknowledging that the ELF concepts introduced to them were eye-opening and thought-provoking, questioned the applicability of these concepts in real-life contexts.

A comparison of the students' and instructor's perspectives reveals that the students' awareness of the existence and importance of different varieties of English matched the instructor's observation. However, the key ELF concept of the ownership of the English language, which was highlighted by the instructor, didn't appear in student interview protocols. It is also not clear whether the participants were aware that varieties of English include those used by non-native speakers, especially those users in the expanding circle, or whether the participants understood that there might be a simplified version of English that facilitates communication between speakers of different first language backgrounds. In addition, the idea that ELF is a non-codified form and is dynamic and changeable didn't surface in the interviews.

In general, the participants in this study, graduate students who were mostly in their initial stage of teaching, seemed to have scratched the surface of ELF after taking their first course on it. This study substantiates Suzuki's (2011) claim that exposure to a single course would not ensure a change of beliefs among teachers or teachers-inpreparation. It also illuminates the point made by Sifakis (2007) about adopting a reflective and transformative approach to raising teachers' awareness of the changing status of English. In sum, this study highlights the need to introduce the concepts of ELF to a wider circle and offer a series of courses in educational contexts in Taiwan.

\section{Acknowledgement}

This study was sponsored by the Ministry of Science and Technology, Taiwan, under grant number NSC 101-2410-H-003-066.

\section{Notes}

1 The number in parentheses shows the data source, with 'I' representing Interview data and the number after the dash indicating participant number.

2 Studio Classroom and Ivy League English are two English language learning magazines commonly adopted by high school teachers as extra learning materials for students. These publications offer short articles and dialogues on various topics. 


\section{References}

Chien, S. 2014. 'Varieties of English: Taiwanese attitudes and perceptions.' Newcastle and Northumbria Working Papers in Linguistics, 20, 1-16.

Dewey, M. 2012. 'Towards a post-normative approach: Learning the pedagogy of ELF.' Journal of English as a Lingua Franca, 1(1), 141-170.

Jenkins, J. 2006. 'Current perspectives on teaching World Englishes and English as a lingua franca.' TESOL Quarterly, 40(1), 157-181.

Jenkins, J., Cogo, A. \& Dewey, M. 2011. 'Review of developments in research into English as a lingua franca.' Language Teaching, 44(3), 281-315.

Kachru, B. B. 1985. 'Standards, codification and sociolinguistic realism: The English language in the outer circle.' In R. Quirk \& H. G. Widdowson (eds.), English in the World. Cambridge: Cambridge University Press, pp. 11-30.

Ke, I. C. \& Cahyani, H. 2014. 'Learning to become users of English as a lingua franca (ELF): How ELF online communication affects Taiwanese learners' beliefs of English.' System, 46, 28-38.
Kirkpatrick, A. 2012. 'English as an Asian lingua franca: The "lingua franca approach" and implications for language education policy.' Journal of English as a Lingua Franca, 1(1), 121-139.

Mauranen, A. 2012. Exploring ELF: Academic English Shaped by Non-Native Speakers. Cambridge: Cambridge University Press.

Sifakis, N. 2007. 'The education of teachers of English as a lingua franca: A transformative perspective.' International Journal of Applied Linguistics, 17(3), 355-375.

Suzuki, A. 2011. 'Introducing diversity of English into ELT: student teachers' responses.' ELT Journal, 65(2), 145153.

Tsou, W. \& Chen, F. 2014. 'EFL and ELF college students' perceptions toward Englishes.' Journal of English as a Lingua Franca, 3, 363-386.

Wang, C. \& Ho, C.T. 2013. 'Impact of International education on students' attitude toward English as lingua franca.' In X. Shao (ed.), Proceedings of International Academic Workshop on Social Science, Amsterdam: Atlantis Press, pp. 762-766. 